\title{
Low cost of sustainable work and maintenance for offshore wind power speed-increasing device
}

\author{
Wang Fei*, Sun Shijie \\ College of Energy and Mechanical Engineering, Shanghai University of Electric Power, Shanghai 200090, China
}

\begin{abstract}
For the problem of wind turbine outage caused by the failure of wind power transmission devices, we proposed an offshore wind power transmission device with low sustainable operation and low maintenance cost. Through the combination of gearbox A and B, the power transmission of the offshore wind turbine is uninterrupted, and the continuous operation of grid-connected power generation enhances the economic benefits of offshore wind turbines. The maritime maintenance man-hours is reduced by moving the speed increase gearbox A from the offshore wind turbine site to the land for maintenance inspection, and the maintenance cost is significantly reduced.
\end{abstract}

\section{Introduction}

In recent years, with the large-scale development of offshore wind power and the grid-connected operation of large-capacity offshore wind turbines, how to operate and maintain offshore wind turbines economically and reliably has become one of the hot issues of new energy research. In the operation and maintenance of offshore wind turbines, it is estimated that nearly $50 \%$ of the outage time is caused by the failure of wind power speed-increasing device ${ }^{[1-2]}$.

The current maintenance strategy is to stop the operation of offshore wind turbines, use marine vessels or helicopters and other means of transport, and inspect and repair or replace the offshore wind turbines on site. Because of the particularity of offshore construction occasions, the current maintenance will cost about 360 hours. The outage of offshore wind turbines does not participate in grid-connected generation, which reduces the economic benefits of offshore wind turbines. The cost of offshore operation is significantly higher than that of land operation, and more time means higher maintenance costs.

We proposed an offshore wind power speedincreasing device with low cost of sustainable work and maintenance. Through the combined use of speed-up gear box $\mathrm{A}$ and speed-up gear box $\mathrm{B}$, the power transmission of offshore wind turbines will not be interrupted during maintenance, and the grid-connected power generation will continue to work, which enhance the economic benefits of offshore wind turbines. Maintenance staff transferred the fault state gearbox A from the offshore wind turbine site to the land for maintenance and inspection, and the maintenance time at sea is reduced, which significantly reduces the maintenance cost of the offshore wind turbine growth.

\section{Current offshore wind power speed- increasing device}

Wind power speed-increasing device is available in a variety of configurations. The small-capacity wind power gearbox adopts the parallel shaft helical gear transmission structure. The common structure of the $500 \mathrm{~kW} \sim 1000 \mathrm{~kW}$ wind power gearbox has two types of parallel axis +1 class planetary and 1 parallel axis +2 class planetary transmission.

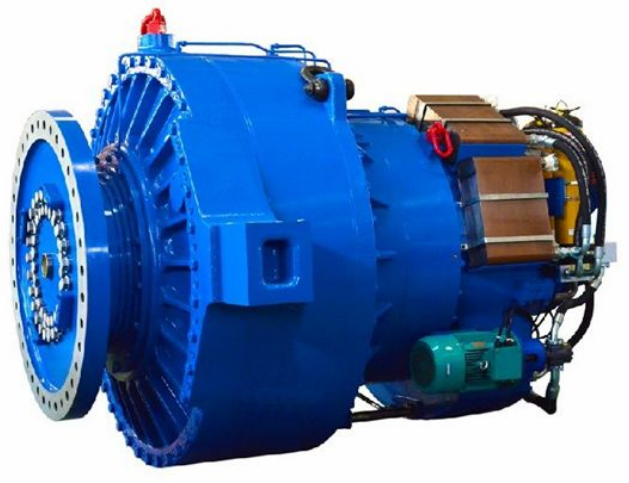

Fig. 1. The schematic diagram of a common type MW class wind power speed-increasing device.

The common type MW class wind power speedincreasing device is shown in Figure 1, which is often used the 2-stage parallel axis +1 planetary transmission. Due to the relatively complicated planetary transmission structure, and the large internal ring gear processing is difficult and costly, even with the 2-stage planetary transmission structure, the NW type transmission is the most common ${ }^{[3]}$.

\footnotetext{
* Corresponding author: urrayu@,163.com
} 
Due to the high concentration of salt spray in the sea, high humidity, and often accompanied by catastrophic weather such as typhoon and sea ice, the operating environment of offshore wind turbines is complex and variable, and is significantly affected by unsteady loads, resulting in high failure rate of wind power speedincreasing devices. In actual operation, the failure of key components (gears, bearings, spindles, etc.) is the most important and most influential equipment failure. In recent years, scholars at home and abroad have carried out a series of investigations on the failure of wind power equipment transmission system, the result of which is shown in Figure 2.

\begin{tabular}{|c|c|c|c|c|c|c|c|}
\hline & $\begin{array}{l}\text { Rolling } \\
\text { bearing. }\end{array}$ & Gear. & $\begin{array}{l}\text { Lubricating } \\
\text { oil. }\end{array}$ & $\begin{array}{l}\text { Hydraulic } \\
\text { pump. }\end{array}$ & $\begin{array}{l}\text { Hydraulic } \\
\text { servo valve }\end{array}$ & $\begin{array}{l}\text { Hydraulic } \\
\text { oil. }\end{array}$ & $\begin{array}{l}\text { Hydraulic } \\
\text { actuator. }\end{array}$ \\
\hline Micropitting & & & & & & & \\
\hline $\begin{array}{l}\text { Rolling } \\
\text { fatigue. }\end{array}$ & & & & & & & \\
\hline $\begin{array}{l}\text { Friction } \\
\text { and wear. }\end{array}$ & & & & & & & \\
\hline Corrosion. & & & & & & & \\
\hline $\begin{array}{l}\text { Frtiction } \\
\text { stagnation. }\end{array}$ & & & & & & & \\
\hline Oxidation. & & & & & & & \\
\hline Stained & & & & & & & \\
\hline
\end{tabular}

Fig. 2. Main factors that cause the failure of wind turbine gearboxes $^{[4]}$.

\section{The component of offshore wind power speed-increasing device with low cost of sustainable work and maintenance}

As shown in Figure 3, low cost of sustainable work and maintenance for offshore wind power speedincreasing device includes the speed-up gear box A, the speed-up gear box B, the input power switching device, the output power switching device, the power supply, the control device, the signal transmitting device, the speedup gear box detection device, the power supply line, the control line and the communication line.

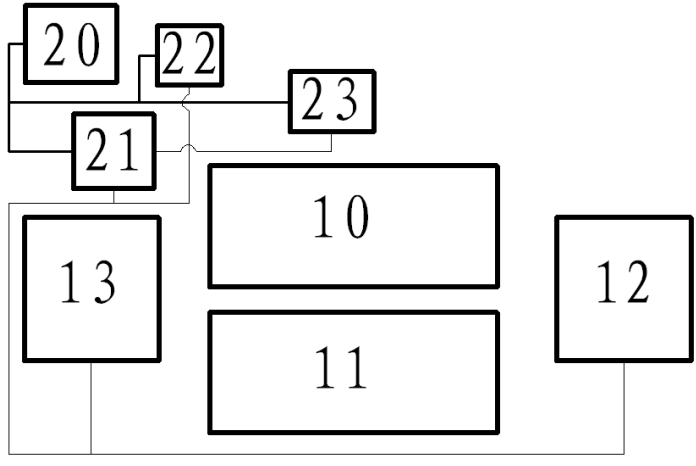

Fig. 3. Component sketch of speed-increasing device. 10-speed-up gear box A, 11-speed-up gear box B, 12-input power switching device, 13-output power switching device, 20-power supply, 21-control device, 22-signal transmitting device, 23-speed-up gear box detection device

The power supply connects the control device, the signal generator and the speed-increasing gear box detection device respectively through the power supply line. The control device connects the power switching device at the input end, the power switching device at the output end and the signal transmitting device respectively through the control circuit. The control device connects the speed-increasing gear box detection device through the communication line.

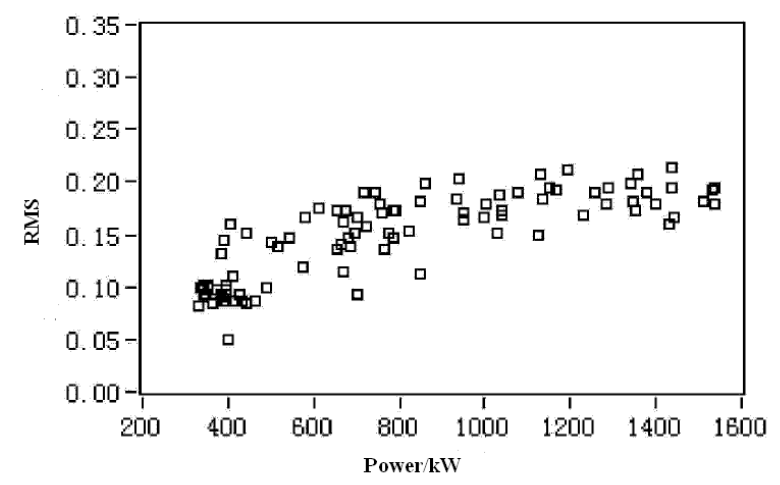

Fig. 4. Relation diagram between meshing vibration energy and generator output power ${ }^{[5]}$.

Among the many strategies of the speed increasing gearbox detecting device, one method can adopt the order spectrum analysis of the vibration signal and the speed pulse signal during the operation of the wind power gear box to obtain the meshing vibration energy, wherein relation diagram between meshing vibration energy and generator output power is shown in Figure 4.

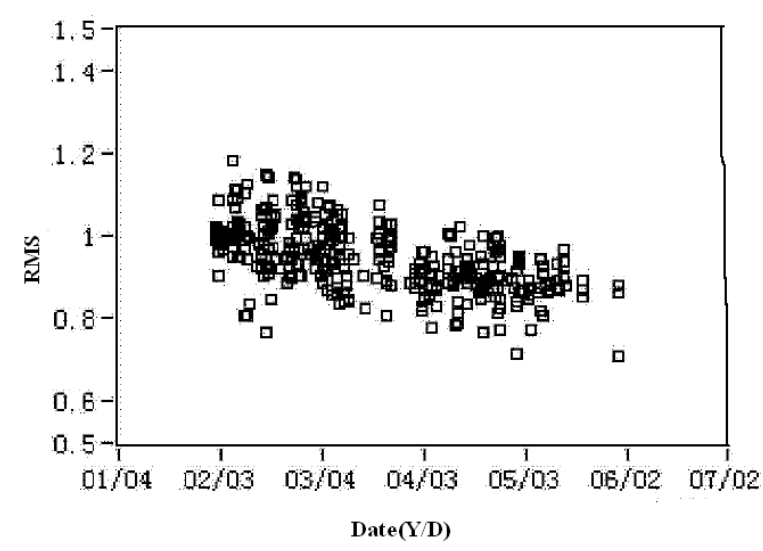

Fig. 5. Normalized real-time meshing vibration energy diagram $^{[5]}$.

Then the meshing vibration energy is further subjected to least squares fitting and means normalization processing, which is based on the quantitative relationship between the meshing vibration energy and the generator output power. Finally, the fault diagnosis of the wind turbine gearbox is analyzed by 
analyzing the normalized real-time meshing vibration energy, which is shown in Figure 5. The method eliminates the interference of the generator output power on the meshing vibration energy and improves the reliability of the fault diagnosis.

\section{Operation method of the device}

\subsection{Normal working condition}

The power supply is turned on first, and the control device, then the signal transmitting device and the speedincreasing gear box detection device are in working state. The control device controls the input power switching device and the output power switching device through the control circuit. The speed-increasing gear box A is in working state, while the speed-increasing gear box B is in standby state, which does not participate in the operation of offshore wind turbines.

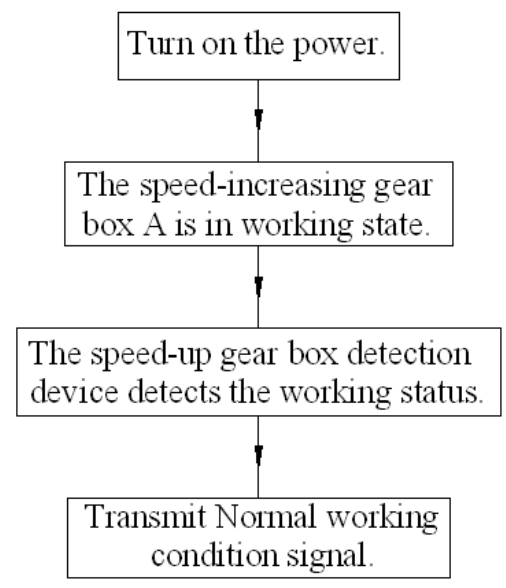

Fig. 6. Flow chart of normal working condition.

The speed-up gear box detection device detects the working status of the speed-up gear box A and transmits the detection signal to the control device through the communication line. When the control device judges the detection signal which shows the working state of the gearbox A is normal, the control device connects the signal transmitter through the control line and transmits signal" The working state of the gearbox A is normal, and Speed-up gear box B standby status.

\subsection{To be replaced state}

According to statistics, the failure of the wind turbine drive system comes from the defects and quality problems of the gear manufacturing process, and most of them originate from fatigue failure. The basic law is as follows: the initial position is from the bearing installation position bearing the severe external load, and the contact fatigue crack and surface wear occur under the action of alternating stress, and the peeling phenomenon occurs; surface wear, debris, gap tolerance and misalignment and other factors promote and amplify each other, affecting the bearing fit; In turn, the operation of the gear is deviated, causing wear, fatigue, gluing and even cracking, eventually leading to gear failure $^{[4]}$.

For some reason, when the speed-increasing gear box detection device signal detected by the control device is judged to be the fault working state of the speedincreasing gear box $\mathrm{A}$, the speed-increasing gear box $\mathrm{A}$ is about to fail. If the speed-increasing gear box $\mathrm{A}$ continues to work, it will lead to the shutdown of offshore wind turbines.

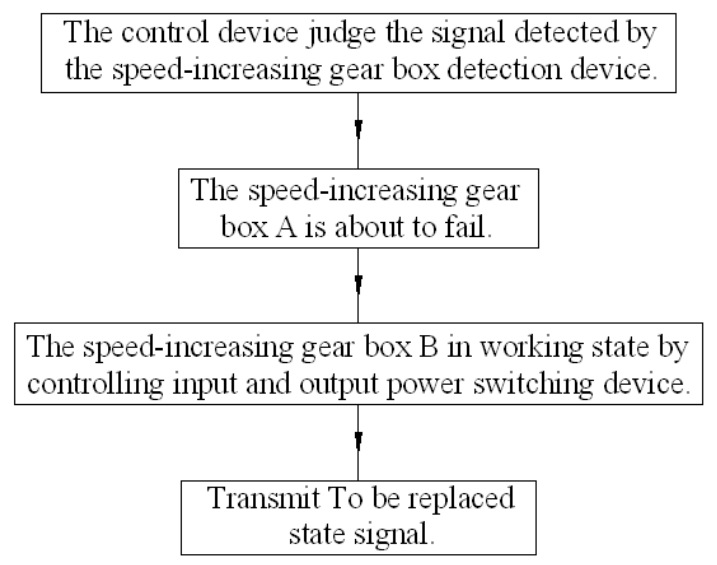

Fig. 7. Flow chart of to be replaced state.

The low cost of sustainable operation and maintenance of offshore wind power growth device adopts the strategy of making the speed-increasing gear box $\mathrm{B}$ in working state, and the speed-increasing gear box $A$ in waiting to be replaced by controlling input power switching device and output power switching device, The speed-up gear box detection device detects the working status of the speed-up gear box B and transmits the detection signal to the control device through the communication line. The control device judges the detection signal, and the working state of the speed-increasing gear box $\mathrm{B}$ is normal. The control device connects the signal transmitter through the control line and transmits signal "The working state of the speed-increasing gear box B is normal, and the speed-increasing gear box A is to be replaced."

\subsection{Fixed normal state}

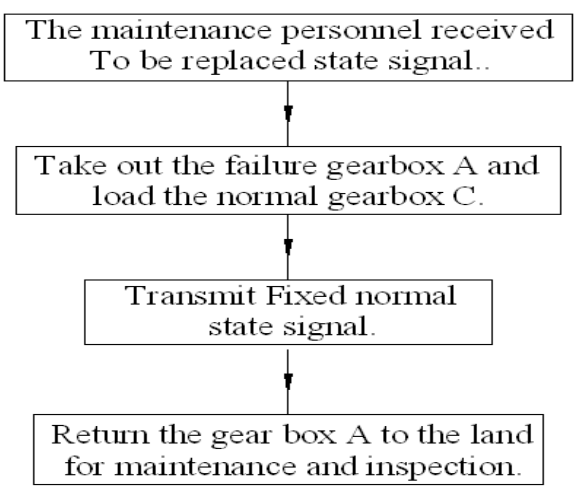


Fig. 8. Flow chart of fixed normal state.

When the maintenance personnel receive the signal, they take out the failure gearbox A and load the normal gearbox C. The control device is set up, and the signal transmitter is connected by the control line to transmit signal "The speed-increasing gear box B works normally, and the speed-increasing gear box $\mathrm{C}$ is spare", Maintenance personnel will return the gear box A to the land for maintenance and inspection. At this time, the sustainable work and the single maintenance of the lowcost offshore wind power speed-increasing device will be completed.

\section{Conclusions}

The offshore wind power increasing device with low sustainable operation and low maintenance cost includes a speed increasing gear box A, a speed increasing gear box B, an input power switching device, an output power switching device, a power source, a control device, a signal transmitting device, and a speed increasing gear box detection device, power line, control line and communication line. During the maintenance period, the offshore wind power transmission device enables the offshore wind turbine to continue working and connect to the grid for power generation. In addition, the gearbox $\mathrm{A}$ in the fault state is transferred from the offshore wind power generation site to the land for inspection and maintenance, which significantly reduces the maintenance cost of the offshore wind turbine generator speed increasing device.

The financial support of this research by Shanghai University of Electric Power introduction talent start fund (A-0201-14-533) is gratefully acknowledged.

\section{References}

1. Y. Ma, J. Chen, R.J. Hong, Y.B. Pan, CHN. Comput. Integra. Manuf. Sys. 25, 2 (2019)

2. D. Xiang, L. Jiang, Y.H. Shen, Y.Z. Wei, CHN. J. Vib. Shock. 37, 11 (2018)

3. L. Y. Zhang, Z.L. Wang, F.G. Liu, CHN. J. Mech. Trans. 32, 6 (2008)

4. H. Wang, X.L. Li, Z. Wang, D.Xiang, Y. N. Rong, CHN. Chin. Mech. Eng. 24, 11 (2013)

5. C. G. Hou, L.J. Dan, Q. Tian, CHN, ZL8201310694994 (2013) 